\title{
Why Menstrual Health and Wellbeing Promotion should not be Sidelined in Africa's Response to COVID-19
}

\author{
Esther Ejiroghene Ajari 1,2,3**
}

\author{
${ }^{1}$ College of Medicine, University of Ibadan, Ibadan, Oyo State, NIGERIA \\ ${ }^{2}$ The TriHealthon, Ibadan, Oyo State, NIGERIA \\ ${ }^{3} \mathrm{G}$ (irls)20, Ontario, Toronto, CANADA \\ *Corresponding Author: estherejiroghene@gmail.com
}

Citation: Ajari, E. E. (2020). Why Menstrual Health and Wellbeing Promotion should not be Sidelined in Africa's Response to COVID-19. European Journal of Environment and Public Health, 4(2), em0045. https://doi.org/10.29333/ejeph/8278

ARTICLE INFO

Received: 26 Apr. 2020

Accepted: 12 May 2020

\begin{abstract}
The COVID-19 crisis has unprecedentedly altered the course of life of majority of Africans. Menstrual health and wellbeing is a key altered aspect. The manifestation of this is apparent in the reduction/elimination of access to Menstrual Hygiene Management products and facilities, adoption of unhygienic menstrual management practices even by healthcare workers, decrease in access to menstrual-related knowledge, increase in the risk of occurrence and severity of several stress-related menstrual disorders, and a shift of public focus from menstrual health and wellbeing promotion. This disruption, in turn, leads to increased risk of predisposition to several other diseases/illnesses; prevalence of medical negligence and error, morbidity and mortality; and development lag in the continent. Prevention of these possible negative outcomes is only feasible through continued and reinforced menstrual health and wellbeing promotion facilitated by the African government and other stakeholders. This paper, thus, aim to redraw their attention to this urgent need.
\end{abstract}

Keywords: COVID-19, Coronavirus, Africa, Menstruation, Menstrual health, Menstrual wellbeing, Health promotion

\section{INTRODUCTION}

The Coronavirus Disease 2019 (COVID-19), caused by the novel Severe Acute Respiratory Syndrome Coronavirus-2 (SARS-CoV-2), was first reported in Wuhan, China on December 31, 2019 (Fan et al., 2020). Since then, there has been expeditious transmission of the virus globally, prompting the World Health Organization to declare the outbreak a pandemic and governments to implement the "stay at home" legislation and other preventive measures. However, these measures were not promptly adopted by several African governments. A repercussion of this delayed response is that it took just 52 days for 51 other African countries to record cases of COVID-19 ever since Egypt recorded the first case in Africa on February 14, 2020 (Shaban and Mumbere, 2020). As at May 12, 2020, Lesotho is the only African country yet to report a case of the disease (Shaban and Mumbere, 2020). This country makes up only approximately $0.18 \%$ of the total African population (Countries in Africa Population, 2020). This implies that the lives of most Africans are being unprecedentedly altered by the pandemic. In an effort to adjust to this reality, alternative (mostly remote and virtual) routes for carrying out essential activities are being explored.
Menstruation is one of such activities but unfortunately, it can neither be experienced via these routes nor can it be put on hold.

Menstruation, the physiological hallmark of reproductive capacity, is experienced on an average of 2-7 days/month by approximately a quarter of the African population (Sommer et al., 2017; UNICEF, 2018) (composed of adolescent girls, premenopausal women, transgender men and non-binary folks) and with it comes an increased demand for personal hygiene and increased vulnerability to several health and wellbeing disorders. Affording the cost of Menstrual Hygiene Management (MHM) is not easy for menstruators globally. Some can barely afford it, others cannot afford it at all. There is no general consensus on the number of African menstruators who fall into the latter category but the reported figures are consistently high. In fact, a 2020 report peg the figure as high as $60 \%$ of the menstruating population (Iroanusi, 2019). The actual figure might even be higher considering that the reports almost never account for the menstruating population who are not girls or women.

The global advocacy for improved menstrual health and wellbeing support has led several African entities to take commendable steps towards achieving this sustainable development goal. For example, the Kenyan Government, in 
2018, approved the free distribution of 140 million menstrual sanitary pads to public school girls in Kenya (Gelardi, 2020), the Nigerian government removed Value-Added Taxation on MHM products effective from January, 2020 (Agbakwuru, 2020) and several African-based charity organizations and well-meaning individuals empowered menstruators with skills to make their own reusable MHM products. However, the COVID-19 pandemic threatens the sustainability and improvement of these efforts. Hence the need for this discourse on why menstrual health and wellbeing promotion is a necessity, not an inessentiality, during this challenging times.

\section{DISCUSSION}

The COVID-19 crisis in Africa has put a considerable strain on a number of menstruators' access to and affordability of MHM products regardless of their usual ability to afford the products. There is a high possibility that during the rush-hour shopping period preceding the lockdown, some menstruators in Africa, just like in other parts of the world, did panic-buying and stocked up on more MHM products than they actually need leading to unavailability of these products (Goldberg, 2020). Unfortunately, restocking of these items was either limited or not possible due to restrictions, necessitated by the pandemic, imposed on businesses by several African governments. Even when limited restocking occurred, some menstruators most likely could not access the products before the lockdown or perhaps, needed the products before they could access them, or accessed but could not afford them (due to the predictable hike in product prices according to the law of demand and supply). Furthermore, in a bid to alleviate the high rate of period poverty in the continent, some interventions provided free access to MHM products for students during school hours, regardless of whether they can afford them or not. However, the COVID-19 imposed lockdown has cut off this access. An implication of this is that these students, who now need to purchase their own MHM products and can afford them, were added to the population of menstruators seeking these products during the rush-hour shopping, thus, further increasing the probability of hoarding and unavailability of these products. Another implication of the lockdown is that the students who cannot afford the products now add up to the already appalling prevalence of period poverty across the continent. Another possibility that might further increase the continent's period poverty rate is the fact that due to the pandemic-associated reduction in income, families or individuals who could barely afford MHM products before the pandemic might prioritize food and some other essential items over these products.

Period poverty is associated with several negative outcomes including desperation on the part of some menstruators, the level of which is emphasized by reports stating that some girls in Kenya, Uganda, Ghana and Zimbabwe trade or have traded sex for MHM products (Adjetey, 2019; Ainebyoona, 2016; Moyo, 2018; Oppenheim, 2018). The COVID-19 crisis can increase the number of menstruators proposing or accepting this trade offer, thus, increasing their risk for contracting Sexually Transmitted
Infections (STI) and experiencing other forms of Sexual and Gender-based Violence (SGBV). Furthermore, it is possible that the "sex for MHM products" trade exist in other African countries even though they are unreported. If this is the case, the incidence of STI and SGBV resulting from this trade will compound Africa's already high STI and SGBV rate which will, in turn, hinder the achievement of sustainable development in Africa. Furthermore, since this form of trade is a, largely, unsuspected risk factor for STI and SGBV, efforts might not be channelled towards curbing it, thus resulting in its persistently high prevalence.

In addition, it should be noted that due to the poor state of Water, Sanitation and Hygiene (WASH) facilities (such as toilets, proper waste disposal facilities etc.) in communities across Africa, a number of girls rely on WASH facilities in establishments such as schools, churches, banks, malls etc. (Tull, 2019) for their MHM. However, the lockdown impedes on this access. The lack of access to these facilities and MHM products increases the vulnerability of menstruators to diseases such as Urinary Tract Infections, Pelvic Tract Infections, mental disorders, Toxic Shock Syndrome etc. Menstruators coming down with these diseases/illnesses is an unwanted outcome even in the pre-COVID-19 Africa but more so during this pandemic considering that a good proportion of healthcare workers meant to manage these diseases/illnesses are at the frontline of the fight against COVID-19 and this leaves them more overworked and stressed than they normally are. This implies an increase in the possibility of medical negligence and preventable medical errors which can lead to morbidity and mortality, in extreme cases. The report that the busy schedule of some frontline healthcare workers and their limited access to preventive suits disallow them from putting on or regularly changing menstrual blood absorbent/collecting materials and carrying out other MHM practices further buttresses this point (Li, 2020). Also, considering that disposable income level has been negatively affected by the pandemic and most healthcare seekers in Africa pay out-ofpocket for these services, requiring healthcare for such preventable disease/illness conditions is not in their best interest financially. In fact, for some individuals, affording these services might not be feasible, thus also possibly leading to morbidity and mortality. These varying possibilities for increasing the morbidity and mortality rate of Africa is a cause for concern considering that this rate is inversely proportional to the availability of human resource in the continent which is a necessary factor for her development.

Moreover, all the previously discussed negative effects associated with MHM negligence are also applicable to healthcare workers. Access to MHM products is also considerably impeded for healthcare workers, especially those at the frontline of response to the COVID-19 pandemic, because of their busy work schedule which might not allow them the luxury of time to shop for these products (Li, 2020). An extreme outcome of the pandemic has also been reported in China where some healthcare workers take oral contraceptive pills to stall their menstrual blood flow (Li, 2020). It is possible that these cases occur in Africa as well but are just unreported. This situation coupled with their poor menstrual management practices, as highlighted in the last paragraph, further justifies the need for maintained, if not 
improved, public focus on menstrual health and wellbeing promotion.

Furthermore, stress levels are reported to be paradoxically high globally (United Nations, 2020) despite the "stay at home" legislation improving the prospect for rest and relaxation during the pandemic. However, this paradox is understandable because sudden and profound disruption of daily activities and sources of income, as seen during this pandemic, is, in itself, a stressor. Furthermore, an argument can be made that the poor level of palliative support provided by African governments to residents of the continent compounds this initial stressor in them. Regardless of what the actual cause of high stress levels are, the fact remains that the crisis-associated stress can disrupt the menstrual cycle and flow in unusual ways (Rathi et al., 2019). However, this disruption should not always be a cause for worry and might not even require any intervention. Also, the crisis can lead to first-time occurrence of stress-associated menstrual disorders such as premenstrual syndrome, premenstrual dysphoric disorder, dysmenorrhea etc. in some menstruators, and increased severity of these disorders in menstruators with previous histories of them (Rathi et al., 2019). The possibility of these unusual outcomes is especially worrisome considering that the crisis has limited the access of menstruators to menstrual-related information. Physical menstrual-related awareness campaigns are no longer possible in most parts of the continent and the attention/priorities of remote/online campaigns organizers might be shifted from the promotion of menstrual health and wellbeing. This situation might not warrant much worry if the taboo against speaking about menstruation had been totally eradicated from Africa. The silence culture surrounding menstruation makes it difficult for menstruators to source for enlightenment on unprecedented changes in their menstrual experience from their friends, peers and even trusted confidants. Furthermore, despite the widearray of information on the subject of menstruation on the internet, most Africans do not have access to these information. This is because less than $25 \%$ of Africans access the internet (Richard, 2018) and some of the population that do access the internet do not source for information from the web. The former case is mostly due to: (a) Their inaccessibility to or unaffordability of internet surfing gadgets, internet connection, electricity etc. (b) Their lack of or inadequate digital literacy skills (c) Lack of contents on the internet in languages they understand (Richard, 2018). The latter case is, perhaps, due to their personal preference for guided education or their wrong assumption that web-sourced information are too technical. In essence, the COVID-19 crisis puts a heavy strain on access to menstrual health and wellbeing education. This, in turn, increases the possibility that menstruators might worry too much about minor and self-limiting stress-related menstrual disorders and/or partake in risky activities in the process of seeking palliation to symptoms of these disorders via the "trial and error" method. The former outcome can, in turn, increase the risk of occurrence of anxiety, depression, fear and other mental disorders which can cycle back to affect one's menstrual health and wellbeing maintenance and surveillance. The latter outcome can lead to morbidity and mortality, in extreme cases.

\section{CONCLUSION}

Previous interventions in the menstrual health and wellbeing promotion sector of Africa have not been optimal enough to compensate for the extended period of "zero or limited interventions" imposed by the COVID-19 pandemic. In an optimal reality, the adequate period of free time offered by the pandemic would not be spent in worry by menstruators but in learning more about themselves, their bodies, potentials, families etc.; improving their human capital; and contributing towards ending the COVID-19 crisis. Therefore, now more than ever before, governmental, organizational and individual efforts need to be consolidated to rapidly and innovatively respond to the growing needs of the menstruating population in Africa and to close loopholes highlighted by other experts before the pandemic and those recently brought to light by the pandemic and highlighted in this paper. Looking into rapid production and distribution of free reusable menstrual sanitary pads might be a good start. Additionally, promoting mindfulness and other contemplative practices which have been shown to relieve stress (Victorson et al., 2015) might be another good step. Furthermore, structures should be put in place to promptly and properly assess future public health concerns and its associated risks in Africa. This is warranted considering that more could have been done during the 45-day window period (between the report of the first COVID-19 case in the world and in Africa) in preventing the rapid spread of the virus across Africa which would, in turn, have prevented the current disruption of menstrual health and wellbeing. However, preventing future negative outcomes is possible.

\section{ACKNOWLEDGEMENT}

The author acknowledges the members of The TriHealthon whom helped with sourcing the data featured in this paper.

\section{REFERENCES}

Adjetey, E. (2019). Ghana's rural girls exchange sex for sanitary pads. Africa Feeds. Available at: https://africafeeds.com/ 2019/12/09/ghanas-rural-girls-exchange-sex-forsanitary-pads/ (Accessed: 16 April 2020).

Agbakwuru, J. (2020). Sanitary pads, 19 others excluded from VAT hike. Vanguard. Available at: https://www.vanguard ngr.com/2020/01/sanitary-pads-19-others-excluded-from -vat-hike/ (Accessed: 12 April 2020).

Ainebyoona, E. (2016). Young girls having sex with older men for sanitary pads. Daily Monitor. Available at: https://www.monitor.co.ug/Magazines/HealthLiving/You ng-girls-having-sex-older-men-sanitary-pads/6898463224108-format-xhtml-he7efsz/index.html (Accessed: 16 April 2020).

Countries In Africa Population. (2020). Available at: http://worldpopulationreview.com/countries/countriesin-africa/ (Accessed: 17 April 2020). 
Fan, J., Liu, X., Pan, W., Douglas, M. W. and Bao, S. (2020). Epidemiology of 2019 novel coronavirus disease in Gansu Province, China, 2020. Emerging Infectious Diseases, 26(6). https://doi.org/10.3201/eid2606.200251

Gelardi, C. (2018). 4 Million Kenyan Schoolgirls Are Going to Receive Free Sanitary Pads. Global Citizen. Available at: https://www.globalcitizen.org/en/content/kenyaschoolgirls-free-pads/ (Accessed: 14 April 2020).

Goldberg, E. (2020). Periods Don't Stop for Pandemics, So She Brings Pads to Women in Need. The New York Times. Available at: https://www.nytimes.com/2020/04/05/us/ 02IHW-virus-tampons-pads-periods-product-shortages. html (Accessed: 14 April 2020).

Iroanusi, Q. E. (2019). With govts failing, Nigerian youth take over fight against 'menstrual period poverty'. Premium Times. Available at: https:/www.premiumtimesng.com/ news/headlines/304364-with-govts-failing-nigerianyouth-take-over-fight-against-menstrual-periodpoverty.html (Accessed: 9 April 2020).

Li, A. J. (2020). How China's coronavirus health care workers exposed the taboo on menstruation. South China Morning Post. Available at: https://www.scmp.com/comment/ opinion/article/3052524/how-chinas-coronavirus-healthcare-workers-exposed-taboo (Accessed: 13 April 2020).

Moyo, J. (2018). Too poor for periods, Zimbabwe's girls rely on rags, paper, leaves. Reuters. Available at: https://www.reuters.com/article/us-zimbabwe-womenmenstruation/too-poor-for-periods-zimbabwes-girlsrely-on-rags-paper-leaves-idUSKBN1KD0MR (Accessed: 17 April 2020).

Oppenheim, M. (2018). Kenyan girls forced into sex in exchange for sanitary products. Independent. Available at: https:/www.independent.co.uk/news/world/africa/kenyagirls-sex-sanitary-products-pads-period-povertya8533081.html (Accessed: 10 April 2020).

Rathi, A. K., Agrawal, M. and Baniya, G. C. (2019). A study of impact of stress: examinations on menstrual cycle among medical students. International Journal of Research in Medicine, 7(12). https://doi.org/10.18203/2320-6012.ijrms 20195542
Richard, S. (2019). 3 reasons why most Africans aren't on the internet - and how to connect them. World Economic Forum. Available at: https://www.weforum.org/agenda/ 2019/08/3-reasons-why-most-africans-arent-on-the-inter net-and-how-to-connect-them/ (Accessed: 18 April 2020).

Shaban, A. R. A., \& Mumbere, D. M. (2020). Coronavirus: Rolling coverage on the impact on Africa; 2020. Africanews, 17 March. Available at: https://www.africanews.com/2020/ 03/17/coronavirus-south-africa-confirms-first-case/ (Accessed: 16 April 2020 2020).

Sommer, M., Phillips-Howard, P. A., Mahon, T., Sasha, Z., Jones, M. and Caruso, B. A. (2017). Beyond menstrual hygiene: addressing vaginal bleeding throughout the life course in low and middle-income countries. BMJ Global Health, 2(2), e000405. https://doi.org/10.1136/bmjgh2017-000405

Tull, K. (2019). Period poverty impact on the economic empowerment of women. Knowledge, Evidence and knowledge for development. Available at: https://assets.publishing.service.gov.uk/media/5c6e87b8e d915d4a32cf063a/period.pdf (Accessed: 13 April 2020).

United Nations International Children's Emergency Fund. (2018). FAST FACTS: Nine things you didn't know about menstruation; 2018. Available at: https://www.unicef.org/ press-releases/fast-facts-nine-things-you-didnt-knowabout-menstruation (Accessed: 11 April 2020).

United Nations. (2020). COVID-19: Mental health in the age of coronavirus. United Nation News, March. Available at: https://news.un.org/en/story/2020/03/1059542 (Accessed: 15 April 2020).

Victorson, D., Kentor, M., Maletich, C., Lawton, R. C., Kaufman, V. H., Borrero, M. and Berkowitz, C. (2015). Mindfulness Meditation to Promote Wellness and Manage Chronic Disease: A Systematic Review and Meta-Analysis of Mindfulness-Based Randomized Controlled Trials Relevant to Lifestyle Medicine. American Journal of Lifestyle Medicine, 9(3), 185-211. https://doi.org/10.1177/ 1559827614537789 